The Development and Initial Validation of a New Scale to Measure Explanatory Style

Katrina M Travers, Peter A Creed, and Shirley Morrissey

School of Applied Psychology and Menzies Health Institute, Griffith University

Contact: Prof Peter Creed p.creed@griffith.edu.au

PAPER CAN BE CITED AS:

Travers, K., Creed, P. A., \& Morrissey, S. (2015). The development and initial validation of a new scale to measure explanatory style. Personality and Individual Differences, 81, 1-6. doi:10.1016/j.paid.2015.01.045 


\begin{abstract}
The reformulated learned helplessness (RLH) theory and its associated construct of explanatory style have been tested extensively using the Attributional Style Questionnaire (ASQ: Peterson et al., 1982) against outcomes such as depression. However, support for the RLH is best described as inconclusive. This is because: (a) the internality dimension is poorly defined and the internality items have poor reliability and validity; (b) the ASQ has not been demonstrated to have structural validity; and (c) the definitions of explanatory style are inconsistent across studies. For these reasons, the RLH theory does not meet the criteria of a “good theory” (Epstein, 1973). The current study was conducted with the goal of developing a valid and reliable measure of explanatory style. The new measure met simple structure when tested using exploratory and confirmatory factor analyses, and each short subscale had acceptable internal reliability. Further, convergent validity with the General Health Questionnaire - 12 was partially demonstrated. Implications for theory and practice are discussed.
\end{abstract}

Keywords: Explanatory style, reformulated learned helplessness theory, Attributional Style Questionnaire 


\section{The Development and Initial Validation of a New Scale to Measure Explanatory Style}

The reformulated learned helplessness (RLH) theory (Abramson, Seligman, \& Teasdale, 1978) is a widely used cognitive model proposing that negative psychological consequences (e.g., depression) are likely when a person is pessimistic when explaining the cause of an unexpected negative event. This pessimism has been defined as an explanatory style that is generalising (global), pervasive (stable), and personal (internal). To investigate this model, Peterson et al. (1982) developed a measure of explanatory style known as the Attributional Style Questionnaire (ASQ). The ASQ has been used almost exclusively to measure a person’s explanatory style.

However, the ASQ has returned inconclusive results within these investigations, which means that the validity of the RLH theory has been poorly supported. The reasons for this poor support include: correlations between the ASQ subscales and outcomes such as depression have been non-significant or weak, particularly the correlations with the internality subscale (Bennett \& Elliott, 2002; Dua, 1995; Gibb, Zhu, Alloy \& Abramson, 2002; Luten, Ralph, \& Mineka, 1997; Michelson, Bellanti, Testa, \& Marchione, 1997; Volpe \& Levin, 1998); structural validity of the ASQ has not delineated a parsimonious model-of-fit reflecting the construct of explanatory style (Furnham, Sadka, \& Brewin, 1992; Kleim, Gonzalo, \& Ehlers, 2011; Proudfoot, Corr, Guest, \& Gray, 2001; Smith, Caputi, \& Crittenden, 2013; Xenikou, Furhham, \& McCarrey, 1997); and research has been inconsistent in the way that explanatory style has been defined.

Although Abramson et al. (1989)'s solution to revise the RLH theory to the HD theory has received some support, the mixed results summarised for the RLH could be due to the problematic internality dimension in the ASQ. Thus, a revised internality scale with new items is required so that the RLH model can be assessed, as it has been defined, along the three explanatory style dimensions. Thus, the goal of the current study was to develop an 
alternative measure of explanatory style that incorporated new internality items. The availability of a valid and reliable scale to assess explanatory style will allow the RLH construct to be measured in a consistent fashion, according to its definition.

\subsection{The Internality Dimension Items}

The internality dimension items have been previously revised, with the aim of increasing its internal consistency. Kinderman and Bentall (1996) suggested that internality be understood as three loci: an internal locus, an external-personal locus, and an externalsituational locus. They found weak to acceptable internal consistency coefficients for this revision ( 0.61 for positive-situational locus to 0.76 for negative situational locus). However, this revision does not lend itself to interpretation as reflecting explanatory style, and the items do not reflect the internal-external dichotomy that typifies the items used for the other dimensions of the ASQ. We propose to revise the internality items using Lewin's (1936) life space theory to guide item development, since this was the original theory used to conceptualise internality (Weiner et al., 1971).

Briefly, Lewin theorised that a person's behaviour (B) is best understood by viewing it as a function of the person themselves (P) and the environment (E) (Back, 1992). Lewin proposed the equation $\mathrm{B}=f[\mathrm{P}, \mathrm{E}]$ to mathematically understand a person's behaviour in the social environment (Back, 1992). It was this understanding that influenced the conceptualisation of internality by Weiner et al. (1971) in their attribution theory (i.e., person/environment), and subsequently the internal/external dichotomy in the explanatory style construct (Abramson et al., 1978).

From this frame-of-reference, we proposed re-writing the items for the internality dimension to reflect each of the three life space domains, with each item to be anchored by the internal/external dichotomy so as to be consistent with the existing item structure of the ASQ. This step would generate items that would reflect a more comprehensive 
reconceptualization of the internality dimension and be interpretable within the construct of an optimistic or pessimistic explanatory style.

\subsection{Structural Validity of the ASQ}

Previous attempts to find structural validity of the ASQ have not been successful. Kleim, Gonzalo, and Ehlers (2011) found only one factor using exploratory factor analysis (EFA), Corr and Gray (1996), Higgins, Zumbo, and Hay (1999), and Proudfoot, Corr, Guest, and Gray (2001) found two factors, and Xenikou and Furnham (1997) found three (interpreted as two positive factors and one negative factor). Higgins et al. (1999) argued that these previous attempts have not been successful because researchers have not taken into consideration the inbuilt "testlets" or common item stems (also known as context-dependent item sets, CDIS) which generate co-variation among items of the same stem if not allowed to correlate when conducting factor analyses of the ASQ. Higgins et al. (1999) suggested that error terms in confirmatory factor analysis be allowed to correlate in order to address this. We addressed this issue by reformatting the ASQ so that each item stem is answered by only one item, thereby eliminating the co-variation due to CDIS. Finally, since Xenikou and Furnham (1997) identified factors representing the positive and negative item stems, we focus only on the negative item stems in order to avoid the confound introduced by having both negative and positive item stems.

\subsection{Objectives}

Thus, this investigation was conducted to achieve four aims: (a) to generate new internality items to reflect the underlying life space theory, (b) to create a unique item stem for each item in order to eliminate the co-variation due to CDIS, (c) to establish initial reliability and structural validity for the revised scale, and (d) to establish initial convergent validity of the scale. 
To achieve these aims, a three phase study was completed. Phase 1 had the goal of generating sufficient negative item stems and items. Phase 2 had the goal of reducing the number of items in each subscale using item analysis and exploratory factor analysis (Kline, 2000) so that each dimension was represented by the least number of items without compromising its reliability (Cook, Hepworth, \& Warr, 1981). A further goal was to establish the initial structural validity of the revised scale using exploratory factor analysis. Finally, Phase 3 had the goal of confirming the structure of the scale generated in Phases 1 and 2 using confirmatory factor analysis, and investigating initial convergent validity.

\section{Phase 1}

\subsection{Materials and Methods}

2.1.1 Participants. Six academic psychologists with doctorate level training (5 females and 1 male) from the university in which the research was conducted, volunteered for Phase 1 (ages ranged from 25 to 55 years).

2.1.2 Procedure. Thirty new items (six each for negative globality, negative stability, and the personality, behaviour, and environment lifespace domains) were generated deductively. These new items were then added to the 12 original negative globality and stability items, resulting in 42 items, thereby allowing enough items to permit redundancy during the item and factor analysis (Hinkin, Tracey, \& Enz, 1997). In addition, we generated 36 new negative item stems, to add to the existing six negative item stems, thereby allowing each item to be preceded with a unique item stem. The original 7-point Likert-type response format was retained, since this scaling technique has been shown to generate the variance necessary for examining the relationships among items and scales and generate adequate reliability estimates (Hinkin et al., 1997).

To assess content validity, the items and item stems were presented in a focus group of the six academic psychologists (Greenbaum, 1993). This resulted in some item and stems 
needing revision. Then a second focus group was conducted with the same academic psychologists with the aim of again assessing the suitability of the items and their stems.

\section{Phase 2}

\subsection{Materials and Methods}

3.1.1 Participants. Three hundred and twenty volunteers participated in Phase 2: 248 participants (77.5\%) were first year psychology students (189 females), and 72 (22.5\%) were community members (49 females). Ages ranged from 18 years to 59 years $(M=25.82, S D=$ 10.25).

3.1.2 Materials. Participants completed the 42 items derived from Phase 1, which were designed to measure the three negative constructs of globality, stability and internality (with rewritten internality items and stems). The response format was a 7-point Likert-like scale anchored at each end with a description of the dimension that it was designed to measure, for example, from an internal/external frame-of-reference. A sample item format is in Figure 1 below.

\section{INSERT FIGURE 1 ABOUT HERE}

3.1.3 Procedure. Surveys were distributed to volunteering students in class, and were given the choice of completing it immediately, or taking it away with them to complete.

Distribution of surveys to community respondents was by way of the snowballing procedure. All respondents were given a reply paid addressed envelope to return the completed scale, and were treated in accordance with the university’s Human Research Ethics Committee guidelines.

\subsection{Results}

3.2.1 Item Analysis. Item distributions, inter-item correlations, and item-total correlations were used to assess for problematic items. Any items with poor distributions or 
inter-item and item-total correlations at $r \leq .20$ were removed. These procedures resulted in the deletion of 12 items, leaving a total of 30 items for exploratory factor analysis procedures.

3.2.2 Exploratory Factor Analysis. The remaining 30 items (ten globality, ten stability, and ten internality items), were analysed using principal components analysis (PCA). Three components were selected to be extracted. The KMO measure of sampling adequacy for this analysis was adequate (.79) and the Bartlett's Test of Sphericity was significant $(<.001)$. Items were retained if they returned factor loadings $\geq .30$, resulting in the deletion of four globality, four stability, and two internality items. A further two internality items with the lowest component loadings were eliminated, leaving six items per dimension. A second analysis resulted in a three component solution that met simple structure, and accounted for $50.4 \%$ of the variance. The resultant three components were interpretable as "negative globality”, “negative stability”, and "negative internality”. The final eighteen items, their factor loadings and summary statistics are reported in Table 1.

\section{INSERT TABLE 1 ABOUT HERE}

\section{Phase 3}

\subsection{Materials and Methods}

4.1.1 Participants. Four hundred and nine participants volunteered for Phase 3: 258 (59.7\%) were first year university students (181 female, age range 17 to 51 years, $M=20.65$, $S D=5.46)$ and 151 (35\%) were community members (89 female, age range 16 to 76 years, $M$ $=36.28, S D=14.18)$.

4.1.2 Materials. The participants completed two scales: the 18-item explanatory style scale devised in Phase 2 and the General Health Questionniare-12 item (GHQ-12; Goldberg \& Williams, 1988).

The GHQ-12 is a general measure of psychiatric disturbance, including negative affect, suitable for use with community members (Goldberg \& Williams, 1988). It consists of 
12 items rated along a 4-point scale from not at all to more than usual with higher scores indicating more distress. It has good internal reliability $(\alpha=.89$; Hardy, Shapiro, Haynes, \& Rick, 1999) and good convergent validity. For example, positive correlations with fatigability, and strong correlations with the GHQ-12 interview version (Hardy et al., 1999). Internal reliability for the GHQ-12 in the current study was .85.

4.1.3 Procedure. The scale administration and storage procedures adopted in section 3.1.3 were also adopted here.

\subsection{Results}

4.2.1 Confirmatory Factor Analysis. Prior to the analysis, 13 cases were deleted due to extensive missing data, leaving 396 cases for analysis.

We used maximum likelihood estimation (AMOS; V17) to test a model that included three latent variables (negative globality, stability, and internality), each with six observed variables. All latent variables were allowed to correlate freely. Model fit was assessed by chisquare, the Goodness-of-Fit Index (GFI) and the Comparative-Fit-Index (CFI). Cut-off values of $>.90$ were considered to be an acceptable model fit (Byrne, 2001). The Root Mean Square of Approximation (RMSEA) index was also used, with cut-off values $<.05$ considered an excellent fit (Byrne, 2001).

The fit statistics for the initial model were $\chi^{2}(126, N=396)=185.27, p<.001$, GFI $=.95, \mathrm{CFI}=.96, \mathrm{RMSEA}=.04$. This indicated an acceptable fit, although the standardised regression weights indicated that four observed variables had non-significant factor loadings $<$.3. These were removed. Subsequent examination resulted in an improved fit, $\chi^{2}(72, N=$ 396) $=114.60, p<.001, \mathrm{GFI}=.96, \mathrm{CFI}=.97, \mathrm{RMSEA}=.04$. In order to achieve an equal number of items (four) in each subscale, the items with the lowest eigenvalue in the globality and stability subscales were removed, resulting in a final fit of $\chi^{2}(50, N=396)=68.6, p$ 
$<.05, \mathrm{GFI}=.97, \mathrm{CFI}=.98, \mathrm{RMSEA}=.03$. Standardised regression weights ranged from .50 to .82 (stability), .39 to .72 (internality) and .43 to .79 (globality).

The inter-correlations among the latent variables were non-significant to weak (globality $\mathrm{x}$ stability $=.26, p<.01$; globality $\mathrm{x}$ internality $=.09, p=.07$; stability $\mathrm{x}$ internality $=-.05, p=.28$ ), indicating that the latent variables are largely independent of one another, adding support for the construct validity of the new scale. Summary statistics and internal consistency coefficients for each subscale and the overall scale are reported in Table 2. All alpha coefficients remain within acceptable levels for four item subscales.

\section{INSERT TABLE 2 ABOUT HERE}

4.2.2 Second Order CFA. We considered a $2^{\text {nd }}$ order CFA to assess if the three could be represented as a single, higher level factor, but his was not conducted as the latent variables were not all significantly inter-correlated, which violates the assumptions of a $2^{\text {nd }}$ order structure (Byrne, 2001).

4.2.3 Construct Validity. The construct validity of the new scale was tested further by correlating subscale and total scores of the new scale with total scores from the GHQ-12. Results demonstrated partial support for construct validity. The globality $(.15, p<.05)$ and stability $(.13, p<.05)$ subscales, as well as the composite score $(.13, p<.05)$ were weakly but significantly correlated with the GHQ-12. However, the internality subscale was not significantly correlated with GHQ-12 (-.08, $p>.05)$.

Since the internality subscale did not directly correlate with the GHQ-12, we tested its indirect associations using moderation analysis as recommended by Baron and Kenny (1986). Internality as a predictor variable was entered at Step 1. Globality and stability as moderator variables, was entered at Step 2, and the interaction terms were entered at Step 3. None of the interaction terms were significant, indicating that internality is not associated with depression, either directly or indirectly. 


\section{Discussion}

The current study set out to devise a new explanatory style scale that would overcome problems associated with earlier scales, such as the ASQ (Peterson et al., 1982), by creating new internality items reflecting the life space theory by Lewin (1936), and redesigning the item format in order to minimise correlated errors due to the common item sets. In this process, we tested the initial structural validity of the new scale and assessed construct validity against depressive symptomatology in a non-clinical sample.

In Phase 1, the new items were tested for content validity by having them reviewed by experts in the field. Using the same procedure and validation process, we devised individual item stems for each question. This allowed each item to refer to one item stem, thereby eliminating potential covariance that could result from multiple items being linked to one stem.

In Phases 2 and 3, using both EFA and CFA techniques, we demonstrated initial support for structural validity for the scale, and demonstrated partial support for construct validity by testing the associations with the GHQ-12.

This is the first study that has attempted to address the structural validity of a measure of explanatory style by reformatting the ASQ in this way, and is thus the first study that has been successful in achieving acceptable structural validity for a measure of explanatory style using EFA techniques, and confirming the structure with CFA techniques. Finally, the initial partial convergent validity results found in Phase 3 replicates previous research into the construct validity of explanatory style with other outcome variables, in particular generally finding no significant direct or indirect associations between the internality dimension and outcome variables (Luten, Ralph, \& Mineka, 1997; Michelson, Bellanti, Testa, \& Marchione, 1997; Volpe \& Levin, 1998). 
The results of this study were interpreted as evidence for the construct validity of the hopelessness theory of depression, rather than the RLH theory of depression. This argument is based on the result that a significant relationship was not found between the internality dimension and depression, either directly or indirectly, despite using an improved measure of explanatory style with acceptable structural validity and content validity for the internality dimension.

The newly devised measure of explanatory style will be a useful tool for those researchers and clinicians interested in investigating the relationship that the individual attributional dimensions of globality, stability and internality have on outcome variables. However clinicians may wish to consider only individual dimensions to describe the explanatory style of a particular individual.

Interpretation of the current results needs to take into consideration the limitations, including the dominance of young, female, adult students, and the lack of diversity in the participant pool and experimental setting.

Since the structural, content, and construct validity of the new scale has been partially established, and improved alpha coefficients have been shown for all dimensions of the new scale, future research needs to: (a) further establish the convergent validity of each dimension against outcomes that explanatory style is theorised to be associated with such as depression, achievement, and ill health; and (b) examine the utility of interpreting results at the dimensional level only.

\subsection{Conclusions}

In summary, the current study was successful in establishing an internally reliable and structurally valid measure of each explanatory style dimension, with four items each. The new scale has promising to acceptable alpha coefficients for each of its dimensions, including the internality dimension, which is an improvement from previous studies in this area. The 
new scale has partial construct validity with the GHQ-12, finding weak significant correlations for the globality and stability dimensions. The construct validity for the internality dimension was not established, which is consistent with previous empirical research in this area. The new scale is a useful tool for those clinicians and researchers interested in whether a person's presenting mood and/or behaviour is related to negative explanatory dimensional thinking, and it is best interpreted at the dimensional level only.

\section{References}

Abramson, L. Y., Seligman, M. E., \& Teasdale, J. D. (1978). Learned helplessness in humans: Critique and reformulation. Journal of Abnormal Psychology, 87, 49-74. doi:10.1037//0021-843x.87.1.49

Abramson, L. Y., \& Metalsky, G. I. (1986). The Cognitive Style Questionnaire: Measurement of negative cognitive styles about self and consequences. Unpublished Manuscript.

Abramson, L. Y., Metalsky, G. I., \& Alloy, L. B. (1989). Hopelessness depression: A theorybased subtype of depression. Psychological Review, 96, 358-372. doi: 0033$295 X / 89 / \$ 00.75$

Back, K. (1992). This business of topology. Journal of Social Issues, 48, 51-66. doi: 10.1111/j.1540-4560.1992.tb00883.x

Beck, A. T. (1978). Beck Depression Inventory: Revised. Philadelphia, PA: Centre for Cognitive Therapy.

Bennett, K. K., \& Elliott, M. (2002). Explanatory style and health: mechanisms linking pessimism to illness. Journal of Applied Social Psychology, 32, 1508-1526. doi: 10.1111/j.1559-1816.2002.tb01449.x

Byrne, B. M. (2001). Structural Equation Modelling with AMOS: Basic Concepts, Applications, and Programming. New Jersey: Lawrence Erlbaum Assoc. 
Cohen, J., \& Cohen, P. (1983). Applied multiple regression/correlation analysis for the behavioural sciences ( ${ }^{\text {nd }}$ ed.). Hillsdale, NJ: Erlbaum.

Cook, J. D., Hepworth, S.J., \& Warr, P.B. (1981). The experience of work. San Diego, CA: Academic Press.

Corr, P. J., \& Gray, J.A. (1996). Structure and validity of the Attributional Style Questionnaire: A cross-sample comparison. Journal of Psychology, 130, 645-658. doi: 10.1080/00223980.1996.9915038

Dua, J. (1995). Retrospective and prospective psychological and physical health as a function of negative affect and attributional style. Journal of Clinical Psychology, 51, 507-518. doi: 10.1002/1097-4679(199507)51:4<507::AID-JCLP2270510407>3.0.CO;2-P

Epstein, S. (1973). The self-concept revisited or a theory of a theory. American Psychologist, 28, 404-416. doi: 10.1037/h0034679

First, M. B., Spitzer, R. L., Gibbon, M., \& Williams, J. B. W. (1996). Structured Clinical Interview for DSM-IV Axis I Disorders - Patient Edition (SCID-I/P, Version 2.0). New York: New York State Psychiatric Institute, Biometrics Research Department. Furnham, A., Sadka, V., \& Brewin, C. R. (1992). The development of an occupational attributonal style questionnaire. Journal of Organisational Behaviour, 13, 27-39. doi: 10.1002/job.4030130104.

Gibb, B. E., Zhu, L., Alloy, L. B., \& Abramson, L. Y. (2002). Attributional styles and academic achievement in university students: A longitudinal investigation. Cognitive Therapy and Research, 26, 309-315.

Greenbaum, T. L. (1993). The handbook for focus group research. New York, NY: Macmillan.

Goldberg, D. \& Williams, P. (1988). A users guide to the General Health Questionnaire. Windsor, Berks: NFER-Nelson. 
Hardy, G.E., Shapiro, D. A., Haynes, C. E., \& Rick, J. E. (1999). Validation of the General Health Questionnaire-12 using a sample of employees from England's Health Care Services. Psychological Assessment, 11, 159-165. doi: 10.1037//1040-3590.11.2.159

Higgins, N.C., Zumbo, B.D., \& Hay, J.L. (1999). Construct validity of attributional style: Modeling context-dependent item sets in the attributional style questionnaire. Educational and Psychological Measurement, 59(5), 804-820. doi:10.2224/sbp.1999.27.3.221

Hinkin, T. R., Tracey, J. B., \& Enz, C. A. (1997). Scale construction: Developing reliable and valid measurement instruments. The Council on Hotel, Restaurant, and Institutional Education, 21, 100-120.

Kinderman, P., \& Bentall, R. P. (1996). Causal attributions in paranoia and depression: Internal, personal, and situational attributions for negative events. Journal of Abnormal Psychology, 106, 341-345. doi:10.1037//0021-843x.106.2.341

Kleim, B., Gonzalo, D., \& Ehlers, A. (2011). The Depressive Attributions Questionnaire (DAQ): Development of a short self-report measure of depressogenic attributions. Journal of Psychopathology and Behavioral Assessment, 33, 375-385. doi:10.1007/s10862-011-9234-9

Kline, P. (2000). The handbook of psychological testing (2nd ed.). London, UK: Routledge. Lewin, K. (1936). Principals of Topological Psychology. New York, NY: McGraw Hill. Luten, A. G., Ralph, J. A., \& Mineka, S. (1997). Pessimistic attributional style: Is it specific to depression versus anxiety versus negative affect. Behaviour Research and Therapy, 35, 703-719. doi: 10.1016/s0005-7967(97)00027-2

Metalsky, G. I., Halberstadt, L. J., \& Abramson, L. Y. (1987). Vulnerability to depressive mood reactions: Toward a more powerful test of the diathesis-stress and causal 
mediation components of the reformulated theory of depression. Journal of Personality and Social Psychology, 52, 386-393. doi:

Metalsky, G. I., \& Joiner Jr., T. E. (1992). Vulnerability to depressive symptomatology: A prospective test of the diathesis-stress and causal mediation components of the hopelessness theory of depression. Journal of Personality and Individual Differences, 63, 667-675. doi: 0022-3514/92/\$3.00

Michelson, L. K., Bellanti, S., Testa, M., \& Marchione, N. (1997). The relationship of attributional style to agoraphobia severity, depression, and treatment outcome. Behaviour Research and Therapy, 35, 1061-1073. doi: 10.1016/s00057967(97)10011-0

Peterson, C., Semmel, A., von Baeyer, C., Abramson, L., Metalsky, G., \& Seligman, M. (1982). The Attributional Style Questionnaire. Cognitive Therapy and Research, 6, 287-300. doi:10.1007/BF01173577

Proudfoot, J. G., Corr, P. J., Guest, D. E., \& Gray, J. A. (2001). The development and evaluation of a scale to measure occupational attributional style in the financial services sector. Personality and Individual Differences, 30, 259-270. doi:10.1016/s0191-8869(00)00043-x

Smith, P., Caputi, P., \& Crittenden, N. (2013). Measuring optimism in organisations: Development of a Workplace Explanatory Styles Questionnaire. Journal of Happiness Studies, 14, 415-432. doi: 10.1007/s10902-012-9336-4

Sturman, E., Mongrain, M., \& Kohn, P. (2006). Attributional style as a predictor of hopelessness depression. Journal of Cognitive Psychotherapy: An International Quarterly, 20, 447-458. doi: 10.1891/jcpiq-v2014a008

Volpe, N., \& Levin, R. (1998). Attributional style, dreaming and depression. Personality and Individual Differences, 25, 1051-1061. doi: 10.1016/s0191-8869(98)00073-7 
Weiner, B., Frieze, I.H., Kukla, A., Reed, L., Rest, S., \& Rosenbaum, R.M. (1971).

Perceiving the causes of success and failure. Morristown, NJ: General Learning Press.

Xenikou, A., \& Furnham, A. (1997). Attributional style for negative events: A proposition for a more reliable and valid measure of attributional style. British Journal of Psychology, 88, 53. doi:10.1111/j.2044-8295.1997.tb02620.x 
Table 1

Principal Components Factor Estimates and Summary Statistics

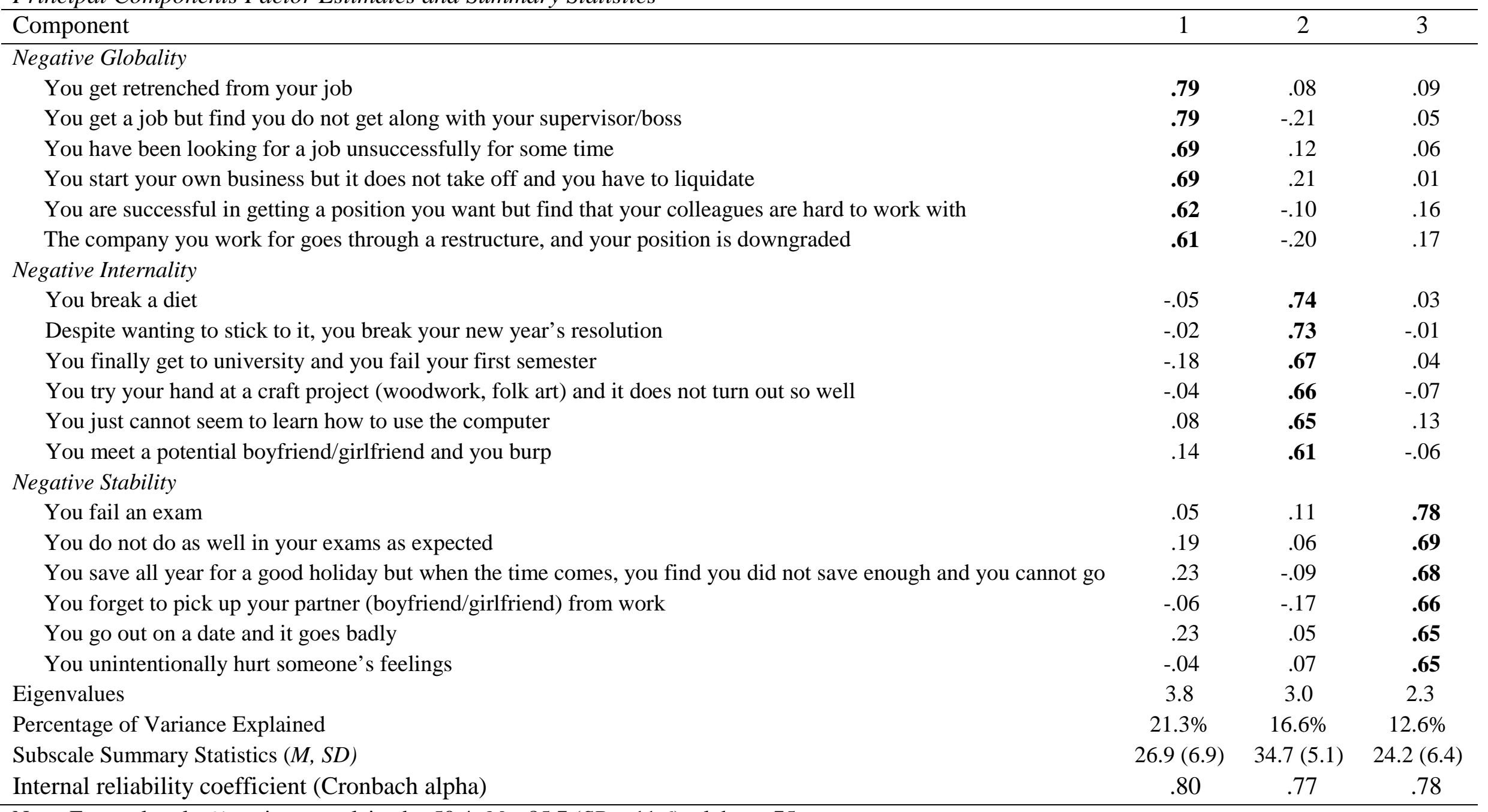

Note: For total scale, \% variance explained = 50.4; $M=85.7(S D=11.6)$; alpha = .75 
Table 2

Summary Statistics and Internal Reliability Coefficients for Subscales and Total Score $(N=$ 396)

\begin{tabular}{lcccccc}
\hline Subscale & $M$ & $S D$ & Alpha & 2 & 3 & 4 \\
\hline Globality & 19.20 & 4.30 & .70 & $.26^{* *}$ & .09 & $.72^{* *}$ \\
Stability & 15.30 & 5.20 & .78 & & -.05 & $.74^{* *}$ \\
Internality & 23.50 & 3.30 & .68 & & & $.41^{* *}$ \\
Composite & 57.90 & 8.30 & .69 & & & \\
\hline
\end{tabular}

$* p<.05 ; * * p<.01 ; * * * p<.001$. 
You break a diet

Is the cause of you breaking a diet due to the personality or character of others', or due to your own personality or character?

Totally due to the

personality or

$1 \quad 2 \quad 3$

34

$4 \quad 5$

6

7

Totally due to my

character of others

own personality or

character

Figure 1. Sample item and item stem from the revised measure of explanatory style. 


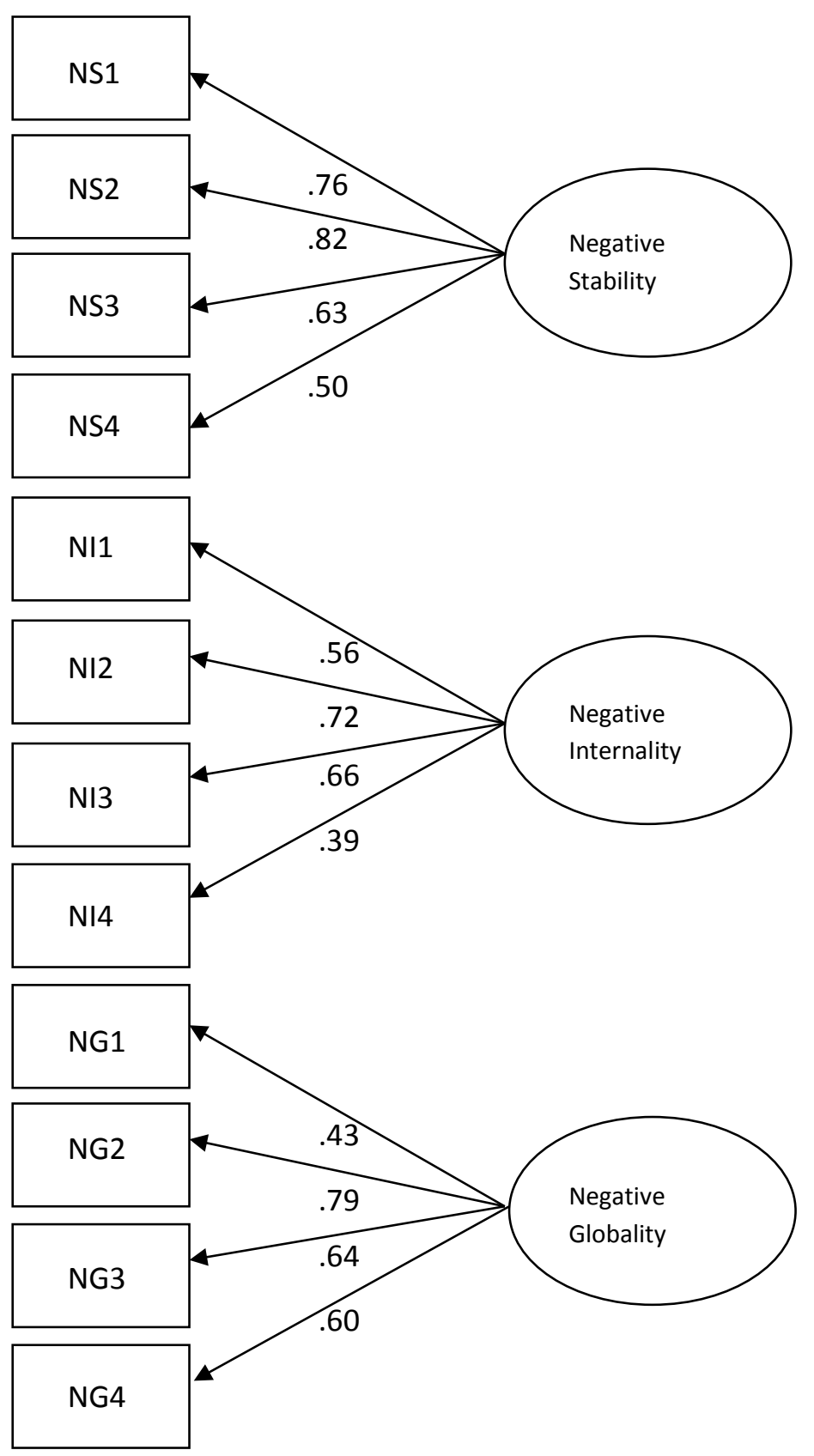

Figure 2. Final CFA solution of the EDS (NG = negative globality, NI = negative internality, and NS = negative stability). 